\title{
Atm Inactivation Results in Aberrant Telomere Clustering during Meiotic Prophase
}

\author{
TEJ K. PANDITA, ${ }^{1 *}$ CHRISTOPH H. WESTPHAL,${ }^{2}$ MELANIE ANGER, ${ }^{3}$ SATIN G. SAWANT, ${ }^{1}$ \\ CHARLES R. GEARD,${ }^{1}$ RAJ K. PANDITA, ${ }^{4}$ AND HARRY SCHERTHAN ${ }^{3}$ \\ Columbia University, New York, New York 10032 ${ }^{1}$; Harvard Medical School, Boston, Massachusetts $02115^{2}$; \\ University of Kaiserslautern, D-67653 Kaiserslautern, Germany ${ }^{3}$; and Albert Einstein College \\ of Medicine, Bronx, New York $10461^{4}$
}

Received 10 February 1999/Returned for modification 1 April 1999/Accepted 13 April 1999

\begin{abstract}
A-T (ataxia telangiectasia) individuals frequently display gonadal atrophy, and $\mathrm{Atm}^{-/-}$mice show spermatogenic failure due to arrest at prophase of meiosis I. Chromosomal movements take place during meiotic prophase, with telomeres congregating on the nuclear envelope to transiently form a cluster during the leptotene/zygotene transition (bouquet arrangement). Since the ATM protein has been implicated in telomere metabolism of somatic cells, we have set out to investigate the effects of $\mathrm{Atm}$ inactivation on meiotic telomere behavior. Fluorescent in situ hybridization and synaptonemal complex (SC) immunostaining of structurally preserved spermatocytes I revealed that telomere clustering occurs aberrantly in $\mathrm{Atm}^{-/-}$mice. Numerous spermatocytes of $\mathrm{Atm}^{-/-}$mice displayed locally accumulated telomeres with stretches of SC near the clustered chromosome ends. This contrasted with spermatogenesis of normal mice, where only a few leptotene/zygotene spermatocytes I with clustered telomeres were detected. Pachytene nuclei, which were much more abundant in normal mice, displayed telomeres scattered over the nuclear periphery. It appears that the timing and occurrence of chromosome polarization is altered in $\mathrm{Atm}^{-1-}$ mice. When we examined telomere-nuclear matrix interactions in spermatocytes I, a significant difference was observed in the ratio of soluble versus matrixassociated telomeric DNA sequences between meiocytes of $\mathrm{Atm}^{-/-}$and control mice. We propose that the severe disruption of spermatogenesis during early prophase $I$ in the absence of functional Atm may be partly due to altered interactions of telomeres with the nuclear matrix and distorted meiotic telomere clustering.
\end{abstract}

Ataxia telangiectasia (A-T) is an autosomal recessive disorder characterized by progressive neurological degeneration, premature aging, growth retardation, specific immunodeficiencies, telangiectasia, high sensitivity to ionizing radiation, genomic instability, cancer progression, and gonadal atrophy $(9,31)$. Cells derived from A-T individuals exhibit a variety of abnormalities in culture such as cytoskeletal defect, hypersensitivity to ionizing radiation, and higher requirement for serum growth factors $(51,78)$. They also show a prominent chromatin defect at chromosome ends in the form of chromosome endto-end associations (also known as telomeric associations) seen at metaphase $(38,61,63,89)$. Chromosome end associations correlate with genomic instability and carcinogenicity $(18,61$, $63)$ and involve telomeres $(48,55)$. Telomeres consist of repetitive (TTAGGG) DNA and proteins which protect chromosome ends from exonucleolytic attack, fusion, and incomplete replication $(7,98)$. Telomere erosion in a variety of cancers and cell lines has been found to lead to chromosome end associations that could contribute to genomic instability and gene amplification (18, 47, 60, 82).

It has been suggested that mammalian terminal (TTAGG $\mathrm{G})_{n}$ repeat arrays interact with the nuclear matrix $(19,44)$. Whether ATM gene effectors influence the interaction of telomeres with the nuclear matrix is not yet known. The ATM protein exhibits the phosphatidylinositol (PI)-3 kinase signature of a growing family of proteins involved in the control of cell cycle progression, processing of DNA damage, and maintenance of genomic stability (32). The protein shows similarity

\footnotetext{
* Corresponding author. Mailing address: Center for Radiological Research, College of Physicians and Surgeons, Columbia University, VC11-213, 630 West 168th St., New York, NY 10032. Phone: (212) 305-3911. Fax: (212) 305-3229. E-mail: tkp1@columbia.edu.
}

to several yeast and mammalian proteins involved in meiotic recombination and cell cycle progression, e.g., the products of MEC1 in budding yeast and $\mathrm{rad}^{+}$in fission yeast and the TOR proteins of yeast and mammals $(35,70,71)$. In yeast, nontelomeric DNA created by enzymatic cleavage leads to genomic instability and cell cycle arrest (69). Because of ATM homology to TEL1 and $\mathrm{rad}^{+}$mutations of yeast, it has been suggested that mutations in ATM could lead to defective telomere maintenance (27). We have recently reported an alteration in both basal and radiation-induced telomeric associations and in mean telomere length in isogenic cells with aberrant ATM function, demonstrating a direct link between ATM function and telomere maintenance (80). A possible hypothesis explaining the defective telomere maintenance in A-T cells could be due to altered interactions between telomeres and the nuclear matrix. An altered interaction between telomeres and the nuclear matrix and nucleosomal periodicity in telomeric chromatin was found in somatic cells derived from A-T individuals (81).

Telomeres have also been considered key structures of meiotic chromosomes $(1,8,20,21,53)$. Meiosis is a specialized cell division that ensures the proper segregation of genetic material and formation of viable haploid gametes. The most critical events of meiosis occur during prophase I, when homologous chromosomes become aligned (prealign), synapse (pair), and recombine with each other. During early meiotic prophase telomeres redistribute and accumulate at a limited sector of the nuclear envelope to form a chromosomal bouquet (for reviews, see references 21, 41, 73, and 94). A number of studies suggest that bouquet formation mediates prealignment of homologues and thereby facilitates synapsis $(17,41,54,67,74,88$, $90,91)$. The only known telomeric proteins that have been implicated in bouquet formation are the products of Tazl of 
fission yeast $(17,58)$ and Ndj1/Tam1 of budding yeast $(15,16$, $67)$.

ATM is a multifaceted protein and is part of a signaling pathway that responds to DNA damage. This pathway involves p53 as well as c-Abl, as A-T null cells are defective in activation of p53 and c-Abl $(6,33,34,37,43,76)$. Accelerated shortening of telomeres in A-T cells and ATM-dependent telomere loss in aging human diploid fibroblasts have been reported (50, 61, 63, $80,93)$. Abrogation of ATM function leads to telomere associations at metaphase (80) and to disruption of gametogenesis due to a meiotic prophase arrest $(3-5,65,96)$. Immunolocalization studies have indicated that the ATM protein is associated with sites along the synaptonemal complex (SC), which are thought to be involved in meiotic recombination $(5,34,66)$. Disruption of Atm in mice leads to severe defects in progression of first prophase and eventually to meiotic arrest and apoptosis $(5,65,96)$. Since telomere clustering at meiosis is thought to bring about prealignment and pairing of homologues (see above) and the ATM mutation influences somatic telomere behavior (80), we investigated meiotic telomere distribution in isolated spermatocytes of mice disrupted in Atm function. Furthermore, we determined the interactions of telomere repeats with nuclear matrix, telomerase activity, and expression of TRF1 (telomere binding factor 1) and several other genes in spermatocytes I of Atm null and control mice. Our results suggest that the failure to disperse clustered telomeres in Atm null mice links with aberrant synapsis and arrest early during meiotic prophase.

\section{MATERIALS AND METHODS}

Mice. For this study, we used mice that are null for Atm (23). The mating pairs for Atm heterozygotes were obtained from Philip Leder, Harvard Medical School, Boston, Mass. The alleles are carried on a mixed genetic background $(129 \mathrm{SvEv} \times$ Black Swiss) mice. The animal colonies were maintained at the animal care facility of Columbia University College of Physicians and Surgeons, New York, N.Y.

Chromosome preparations, cell suspensions, and spreading. Male mice were killed by cervical dislocation. Testicular cell suspensions for Giemsa staining were obtained by immersing dissected fragments of testis tubules for $30 \mathrm{~min}$ in hypotonic $\mathrm{KCl}$ solution of $0.0375 \mathrm{M}$ at room temperature. The seminiferous tubules were then minced with forceps, and large tubular fragments were removed by sedimentation. The turbid supernatant was collected and centrifuged at 1,000 rpm for $5 \mathrm{~min}$. The cell pellet was fixed in methanol-acetic acid (2:1). The suspension was then dropped on prechilled glass slides and air dried. Nuclear morphology of Giemsa-stained cell suspensions was used to identify meiocytes at various stages of prophase I (26).

Nuclear spreading. Freshly obtained testes were dissected in ice-cold minimal essential medium (MEM) and minced until the solution turned turbid. About 50 $\mu \mathrm{l}$ of the turbid solution was placed on a glass slide and mixed with $250 \mu \mathrm{l}$ of $1 \%$ of Triton X-100. The swelling of spermatocytes was monitored with an inverted microscope. When cells obtained an opaque appearance, $300 \mu \mathrm{l}$ of fixative $(4 \%$ formaldehyde, $0.1 \mathrm{M}$ sucrose) was added to the slide and gently mixed by tilting. Slides were air dried at $37^{\circ} \mathrm{C}$ overnight.

Structurally preserved nuclei for simultaneous SC immunostaining and fluorescent in situ hybridization (FISH) were prepared by mincing fresh tissue in MEM (Life Technologies). After removal of tissue pieces, the suspension was immediately mixed with fixative (3.7\% formaldehyde, $0.1 \mathrm{M}$ sucrose) and placed on precleaned slides. After air drying, slides were stored at $-20^{\circ} \mathrm{C}$ until further use (75).

FISH. A chromosome 8 region-specific mouse probe (map position 74 centimorgans) was obtained from Oncor (Gaithersburg, Md.). Hybridization was performed as instructed by the manufacturer. To detect the telomeres, a commercial TTAGGG probe (Oncor) was used for in situ hybridization (60). The number of distinct fluorescent telomeric signals was determined from 100 cells for each genotype. Three-dimensional evaluation of hybridized nuclei was performed in some experiments by focusing through the nuclei with a $100 \times$ plan neofluor lens. Serial sections were obtained from some cases by using a confocal laser scanning microscope.

SC immunostaining. Structurally preserved nuclei were obtained from a testis cell suspension as described above. This suspension was immediately mixed with fixative (3.7\% formaldehyde, $0.1 \mathrm{M}$ sucrose) and placed on precleaned slides. After air drying, the sucrose and formaldehyde were removed by rinsing the preparations repeatedly in phosphate-buffered saline (PBS), and immunostaining of the SCP3 protein of the axial/lateral element of the SC (40) was done as described earlier (75). Briefly, cells were washed with PBS and incubated with antibody solution (rabbit anti-SCP3 polyclonal serum diluted 1/250 in PBS-0.1\% Tween 20) for $60 \mathrm{~min}$ at $37^{\circ} \mathrm{C}$. Cells were rinsed three times for $3 \mathrm{~min}$ each with PBS-Tween 20 and incubated with a secondary goat anti-rabbit Cy3-conjugated antibody (diluted 1/500 in PBS; Vector Laboratories, Inc., Burlingame, Calif.). Cells were again washed with PBS and mounted in antifade solution (Vector Laboratories) containing 4',6-diamidino-2-phenylindole (DAPI; $1 \mu \mathrm{g} / \mathrm{ml}$ ) as DNA counterstain. Preparations obtained by this procedure were also used in immunostaining/FISH experiments, which were performed as described previously (75).

Preparation and digestion of halos with restriction enzyme and detection of TTAGGG arrays. Male mice were killed by cervical dislocation. Freshly obtained testes were dissected in ice-cold MEM and minced until the solution turned turbid. Cells in different phases were enriched by centrifugal elutriation as described previously (62). The fraction containing mostly leptotene/zygotene cells was used for preparation of halos. The procedure used for the isolation of lithium diiodosalicylate (LIS)-generated halo structures is a modification of the LIS technique developed by Mirkovitch et al. (52) and Dijkwel and Hamlin (22). Cells were washed twice with cold PBS and twice with a cell wash buffer (CWB) (50 mM KCl, 0.5 mM EDTA, $0.05 \mathrm{mM}$ spermidine, $0.05 \mathrm{mM}$ spermine, $0.25 \mathrm{mM}$ phenylmethylsulfonyl fluoride, $0.5 \%$ thiodiglycol, $5 \mathrm{mM}$ Tris- $\mathrm{HCl}$ [pH 7.4]) and then suspended in CWB containing $0.1 \%$ digitonin (Calbiochem). The cells were passed through a 20-gauge needle, and lysis was monitored by phase-contrast microscopy. The suspension was loaded on $10 \%$ glycerol cushion in CWB, and the nuclei were washed with CWB containing $0.1 \%$ digitonin, suspended in CWB with $0.1 \%$ digitonin and $0.5 \mathrm{mM} \mathrm{CuSO}_{4}$ but without EDTA, and incubated for $20 \mathrm{~min}$ at $37^{\circ} \mathrm{C}$. LIS solution $(10 \mathrm{mM}$ LIS, $100 \mathrm{mM}$ lithium acetate, $0.1 \%$ digitonin, $0.05 \mathrm{mM}$ spermine, $0.125 \mathrm{mM}$ spermidine, $0.25 \mathrm{mM}$ phenylmethylsulfonyl fluoride, $20 \mathrm{mM}$ HEPES-KOH [pH 7.4]) was added, and the mixture was incubated for $10 \mathrm{~min}$ at room temperature. Halos were collected by centrifugation and washed three times with wash buffer $(20 \mathrm{mM} \mathrm{KCl}, 70 \mathrm{mM} \mathrm{NaCl}, 10 \mathrm{mM}$ $\mathrm{MgCl}_{2}, 10 \mathrm{mM}$ Tris- $\mathrm{HCl}[\mathrm{pH}$ 7.4]) containing $0.1 \%$ digitonin. The nuclear halos were then washed with a restriction enzyme buffer, $6 \times 10^{6}$ halos were cleaved in a volume of $0.5 \mathrm{ml}$ containing $1,000 \mathrm{U}$ of Sty I restriction enzyme for $3 \mathrm{~h}$ at $37^{\circ} \mathrm{C}$, and the nuclear matrices were pelleted by centrifugation. To purify released and attached DNA fragments to nuclear matrix, both fractions were treated with proteinase $\mathrm{K}$ in $10 \mathrm{mM}$ EDTA- $0.5 \%$ sodium dodecyl sulfate $-10 \mathrm{mM}$ Tris- $\mathrm{HCl}(\mathrm{pH} 7.4)$, and incubated overnight at $37^{\circ} \mathrm{C}$. DNA was purified as described recently (81). Agarose gel electrophoresis was performed for the fractionation of DNA (63). For Southern blot analysis, equal volumes from about $10^{6}$ halos were fractionated on $0.8 \%$ agarose gels. Prior to DNA loading, RNase was added to a final concentration of $10 \mu \mathrm{g} / \mathrm{ml}$. Fractionation of DNA, transfer to Hybond-N membrane, hybridization with ${ }^{32} \mathrm{P}$-labeled (TTAGGG) ${ }_{n}$ probe, and detection were done as described previously (63).

Telomerase assay. Telomerase activity was determined by using a telomerase PCR enzyme-linked immunosorbent assay (ELISA) kit (Boehringer Mannheim) as described recently (72). Briefly, testes were dissected, and seminiferous tubules were collected, minced, incubated with collagenase (800 U) and hyaluronidase (200 U), aspirated through 19- to 24-gauge needles and stored frozen at $-80^{\circ} \mathrm{C}$. Cells were washed with cold PBS and lysed in precooled lysis solution (Boehringer Mannheim) by incubating the suspension on ice for $30 \mathrm{~min}$. Samples were microcentrifuged, and protein concentrations of the supernatant were measured with a Bio-Rad protein assay kit. Cell extracts were incubated at $25^{\circ} \mathrm{C}$ in the presence of biotin-labeled primers. The telomeric repeats added onto the ends of the synthetic primers were amplified by PCR. The denatured products were allowed to bind to a streptavidin-coated plate and hybridized to a digoxigenin-labeled, telomeric repeat-specific probe. The biotin-labeled PCR product was detected with a peroxidase-conjugated antibody to digoxigenin and was then visualized by virtue of the enzyme's ability to metabolize trimethylbenzidine so as to produce a colored reaction product. The sample absorbance at $450 \mathrm{~nm}$ measured in an ELISA reader represents telomerase activity in the sample. Telomerase activity was determined in triplicate, and both negative and positive controls were run with each experiment. As a negative control, an aliquot of each extract was heat inactivated for $10 \mathrm{~min}$ at $95^{\circ} \mathrm{C}$.

Determination of TRF1 expression. Two approaches were used to determine the expression of TRF1. In the first approach, testes were collected on dry ice. Total RNA was isolated from testes by using an RNeasy kit (Qiagen, Santa Clarita, Calif.). cDNA was prepared from equal amounts of RNA as described previously (79). The primers used for the amplification of mouse TRF1 were designed from a cDNA sequence (11). Equal amounts of cDNA from different genotypes were used for the PCR amplification and quantification of the mouse $T R F 1$ product. In a second approach, equal amounts of RNA isolated from testes were blotted on the membrane and hybridized with the ${ }^{32} \mathrm{P}$-labeled TRF1-specific probe, which was made from cDNA by using TRF1-specific primers. The conditions for hybridization and detection are the same as described previously (63).

Gene expression profile analyzed with total RNA. We used mouse Atlas cDNA expression arrays (Clontech Laboratories, Palo Alto, Calif.) to determine the differences in the gene expression in male germ cells among $\mathrm{Atm}^{-1-}$ and control mice. Atlas cDNA membrane contains 588 known mouse genes. The procedure for examining the gene expression profile with total RNA was performed as specified by the manufacturer (Clontech). In brief, poly $(\mathrm{A})^{+}$RNA was isolated from the seminal vesicles by using an Oligotex Direct mRNA mini kit (Qiagen). 

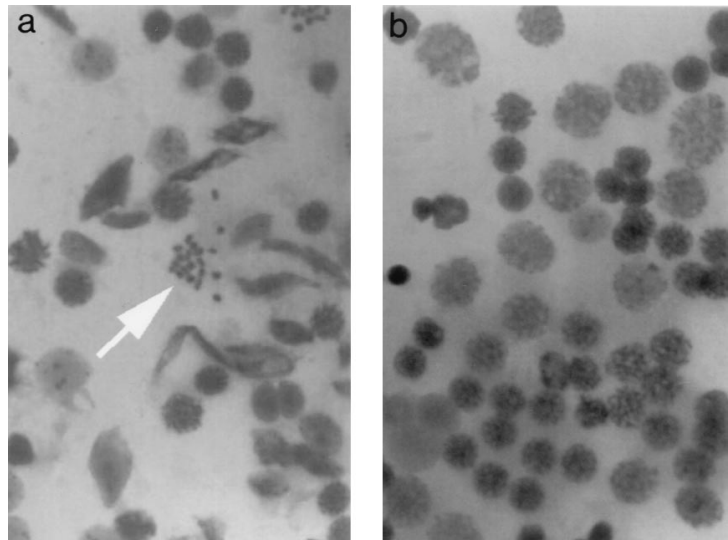

FIG. 1. Giemsa-stained spermatocytes of 42-day-old mice. (a) Control mice show meiosis metaphase I along with other well-differentiated cells of spermatocytes. Arrow denotes bivalents at metaphase I. (b) Preparation from an $\mathrm{Atm}^{-1}$ testicle. Note the absence of condensed bivalents or mature spermatocytes.

The poly $(\mathrm{A})^{+}$RNA was treated with RNase-free DNase I (Boehringer Mannheim) and then used for cDNA synthesis and labeled with ${ }^{32} \mathrm{P}$. The labeled cDNA was hybridized to the Atlas arrays, followed by washing and exposure of the membrane in a PhosphorImager (Molecular Dynamics). The image analysis and quantification were done individually for each dot by using the Scion Image program.

\section{RESULTS}

Spermatogenesis is arrested in prophase $\mathrm{I}$ in $\mathrm{Atm}^{-1-}$ spermatocytes. The progression of the meiotic cell cycle in $\mathrm{Atm}^{-/-}$ and control mice was monitored in Giemsa-stained testicular touch preparations. All stages of meiotic prophase were present in preparations of testicles of 42-day-old control mice (Fig. 1a). In $\mathrm{Atm}^{-1-}$ mice of the same age, spermatogenesis was arrested at the spermatocyte stage, and diplotene or diakinesis as well as spermatids were absent (Fig. 1b). In $\mathrm{Atm}^{-1-}$ mice, the frequency of cells with leptotene Giemsa morphology
TABLE 1. Frequency of spermatocytes detected at the indicated prophase stages in spread spermatocytes of control and Atm $^{-1-}$ mice $^{a}$

\begin{tabular}{lcc}
\hline \multirow{2}{*}{ Prophase stage } & \multicolumn{2}{c}{ Frequency (\%) } \\
\cline { 2 - 3 } & Control & Atm $^{-/-}$ \\
\hline Leptotene & 3 & 4 \\
Zygotene & 13 & 2 \\
Pachytene & 53 & 0 \\
Diplotene & 33 & 0 \\
Aberrant spermatocytes & 0 & 94 \\
\hline
\end{tabular}

${ }^{a}$ One hundred spermatocytes were examined. Aberrant spermatocytes displayed fragmented SCs, pairing partner switches, absence of sex vesicle formation, SC fragments, and unpaired axial cores.

was comparable to that in control mice, while the frequency of zygotene cells was significantly lower than in control mice $(2 \%$ versus $13 \%$ ) (Table 1). Cells with typical pachytene or diplotene morphology were largely absent.

It has been reported that $\mathrm{Atm}^{-1-}$ spermatocytes arrest during prophase I and display aberrant synapsis $(5,65)$. To test whether this is also the case in our $\mathrm{Atm}^{-1-}$, we investigated SC formation by immunostaining of the SCP3 axial/lateral element proteins of the SC (40) in surface spread spermatocytes. Progression of synapsis in control mice appeared to be normal (not shown). In $\mathrm{Atm}^{-/-}$mice, however, a severe deviation from normal synapsis was apparent (Fig. 2; Table 1). The vast majority of spermatocytes of $\mathrm{Atm}^{-/-}$mice were aberrant in all aspects of SC formation and displayed large portions of unpaired axial cores, pairing partner switches, absence of sex vesicle formation (Fig. 2), and fragmented axial cores and SCs (not shown). In comparison to control, 94\% of spread $\mathrm{Atm}^{-1-}$ spermatocytes displayed these features of aberrant synapsis (Table 1), confirming the meiotic phenotype of this mutation.

Undisrupted $\mathrm{Atm}^{-1-}$ spermatocytes I frequently display a bouquet arrangement. Since detergent spreading of spermatocytes I disrupts three-dimensional nuclear architecture like
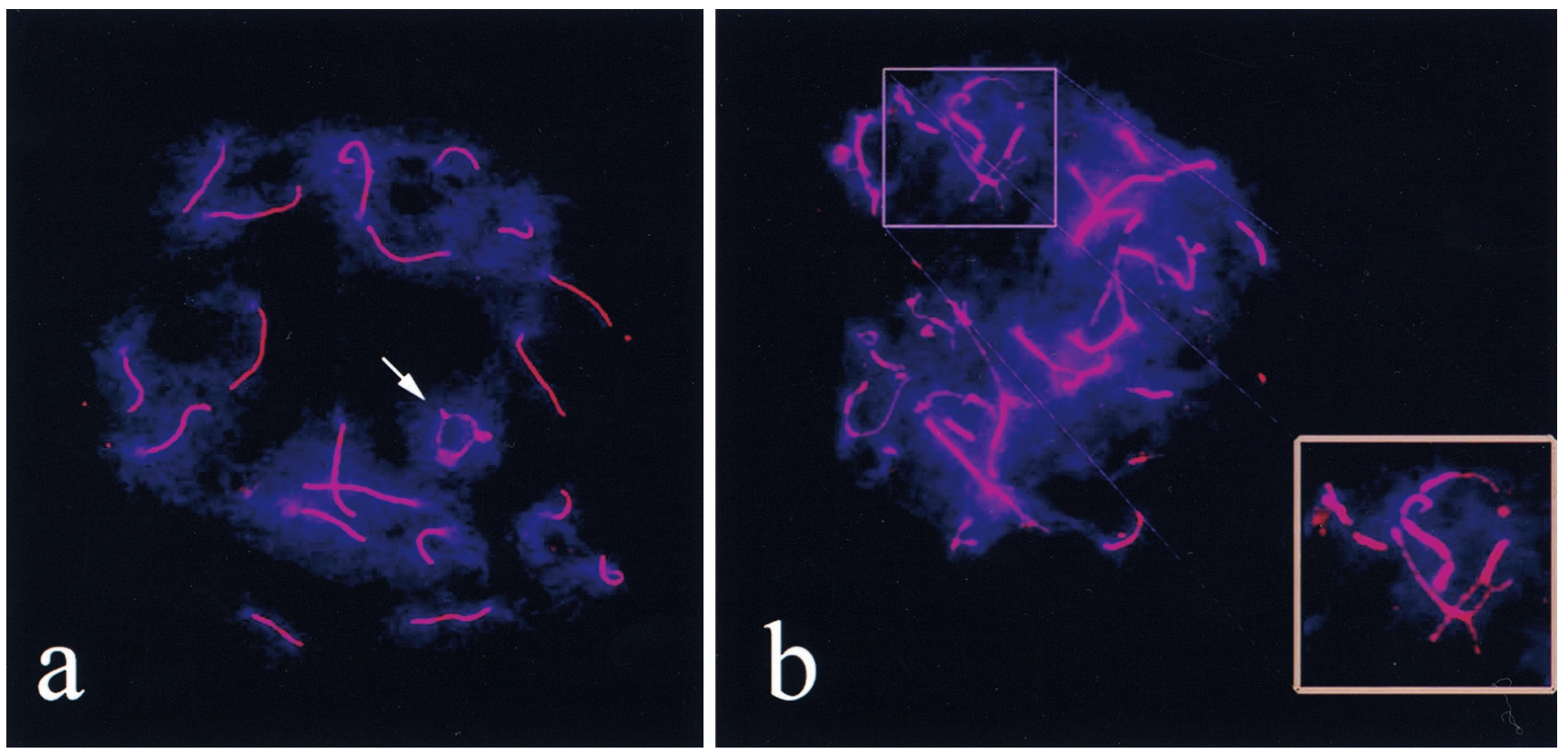

FIG. 2. Spreads of spermatocyte after SC immunostaining with anti-SCP3 antiserum. (a) SC of pachytene spermatocytes of control mice. The arrow indicates the sex vesicles in control spermatocytes. (b) $\mathrm{Atm}^{-1-}$ spermatocytes show aberrant synapsis with unpaired axial cores, nonhomologous synapsis, and fragmented SCs. 
TABLE 2. FISH signal distribution of chromosome 8 subregion in zygotene $^{a}$ of mice with different genotypes

\begin{tabular}{lccc}
\hline \multirow{2}{*}{ Genotype } & \multicolumn{3}{c}{ Signal distribution } \\
\cline { 2 - 4 } & Separated & Aligned & Fused \\
\hline Control & 0 & 22 & 78 \\
Atm $^{-1-}$ & $24^{b}$ & 28 & 52
\end{tabular}

${ }^{a}$ Stages were assigned according to chromatin morphology (26). Pairing of the chromosome 8 subterminal region is reduced in $\mathrm{Atm}^{-/-}$mice.

${ }^{b}$ Separated signals in $\mathrm{Atm}^{-1-}$ mice are significantly different from those in control mice by chi-square analysis $(P<0.05)$.

chromosome polarization, we investigated SC formation in undisrupted spermatocyte I nuclei from $\mathrm{Atm}^{-/-}$and control mice. In doing so, we wished to investigate the frequency of occurrence of spermatocytes at the bouquet stage, as nuclei with large chromocenters which were noted in the Giemsa analysis of $\mathrm{Atm}^{-1-}$ testes suspensions (data not shown) suggested the association of proximal chromosome ends. In normal mouse meiosis, the transient formation of a chromosomal bouquet during leptotene/zygotene discloses such nuclei at a low frequency, even in tissue sections $(25,75)$. In accordance with these observations, SCP3 staining of undisrupted control spermatocytes revealed that all of 226 nuclei showed chromosome ends scattered over the nuclear periphery. Accumulation of a considerable fraction of chromosome ends at a limited region of the nuclear periphery was seen in $2 \%$ of nuclei (Fig. $3 a)$. These results are in agreement with earlier reports in female meiosis (85).

$\mathrm{Atm}^{-1-}$ spermatocytes displayed a severe deviation from this pattern. Numerous spermatocyte I nuclei exhibited a single large chromocenter formed by DAPI bright heterochromatin, usually diagnostic for bouquet nuclei (75). SC immunostaining identified these nuclei as spermatocytes with partial synapsis (Fig. 3d), thereby excluding the possibility that these nuclei
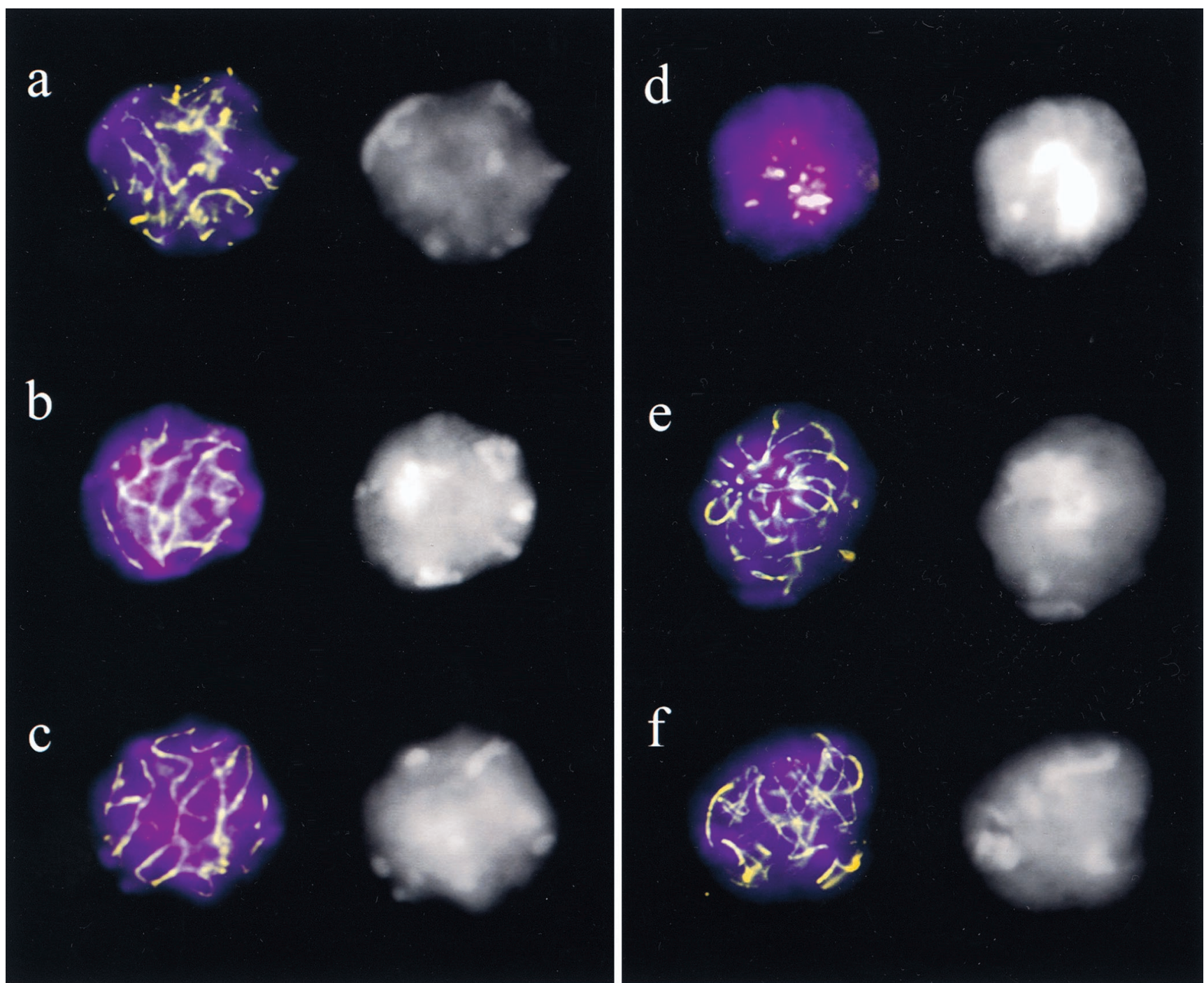

FIG. 3. SCP3 immunostaining (yellowish) to structurally preserved spermatocytes from normal (a to c) and $\mathrm{Atm}^{-/-}$(d to f) testicle suspensions. DAPI images (gray) are shown to the right. (a) Zygotene nucleus with partial synapsis. (b and c) Pachytene nuclei with variously arranged SCs. (d) Atm ${ }^{-/-}$spermatocyte nucleus with a prominent chromocenter (seen as white mass in the DAPI image) and fragments of SC located at the chromocenter (compare with Fig. 5c and d). (e) Atm ${ }^{-/}$ spermatocyte with SCs looping out from the single chromocenter (bouquet arrangement). (f) Aberrant $\mathrm{Atm}^{-1-}$ spermatocyte with long axial elements and few stretches of SCs. 

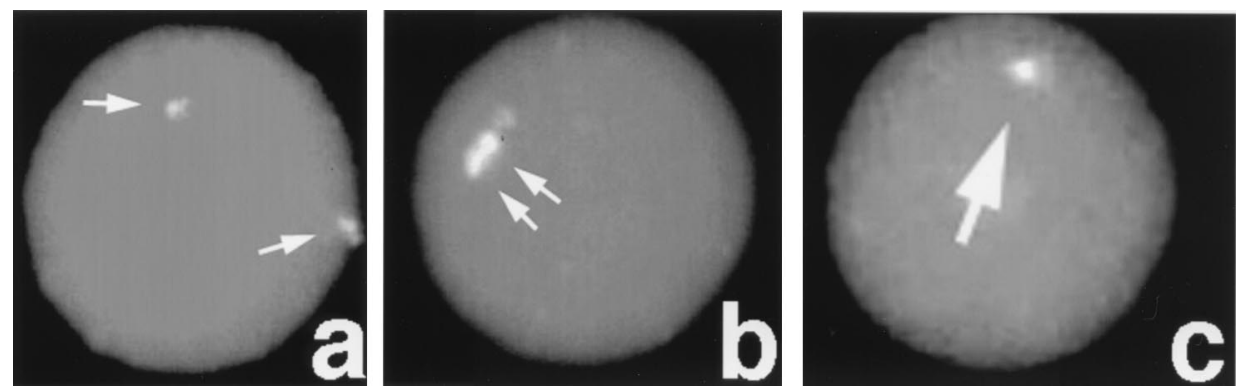

FIG. 4. FISH with chromosome 8-specific proximal probes to Atm proximity; (c) fused signals.

represent aberrant spermatids, which also tend to contain a large chromocenter $(10,30)$. Furthermore, spermatocytes with a fair amount of synapsis and conspicuous polarization of chromosome ends were observed (Fig. 3e), giving rise to a bouquet arrangement during a late zygotene/pachytene equivalent stage. Hence, it appears that the timing and occurrence of chromosome polarization are altered in $\mathrm{Atm}^{-1-}$ mice, since such an arrangement is rarely seen in pachytene spermatocytes of normal mice (Fig. 3b and c) (25).

Pairing of a distal telomere region is reduced in $\mathrm{Atm}^{-/-}$ spermatocytes. It is believed that telomere clustering confers a spatial proximity to homologous chromosomes. Given the aberrant synapsis in Atm-defective spermatocytes, we wished to test whether this mutation influences homologue alignment and pairing. To address this question, we used a mouse chromosome 8 region-specific probe, which maps adjacent to the distal telomere. As shown in Fig. 4, we observed spatially separated, aligned, and fused chromosome-specific signals in early prophase spermatocytes of all mutant and normal mice (Table 2). Comparison of the frequency of cells with separated, aligned, and fused signals among $\mathrm{Atm}^{-1-}$ and control mice, however, revealed that $\mathrm{Atm}^{-1-}$ mice had significantly higher frequencies of cells with separated signals compared to control mice. These results suggest that the early prophase arrest seen in $\mathrm{Atm}^{-1-}$ mice leads to a reduction of homologue pairing even at telomeric regions. Still, a considerable fraction of $\mathrm{Atm}^{-1-}$ spermatocytes displayed paired signals, which could be mediated by the persisting bouquet arrangement.

Sustained chromosome polarization occurs at high frequency in $\mathrm{Atm}^{-1-}$ spermatocytes. Since the above observations suggest a link between the Atm mutation and an altered telomere distribution at meiosis, we investigated the occurrence and frequency of telomere cluster formation in $\mathrm{Atm}^{-1-}$ testes suspensions by telomere repeat FISH alone and in conjunction with SCP3 immunostaining. First, telomere distribution patterns were investigated in spermatocytes fixed with acetic acidmethanol (1:3) and counterstained with propidium iodide. This procedure detected various stages of telomere clustering and dispersion during prophase I (Fig. 5). In control mice (Fig. 5a and $b$ ), the frequency of spermatocytes with telomere clustering was about $0.7 \%$, while cells with a pachytene chromatin morphology and dispersed telomeres were abundant (Fig. 5d to f). In contrast, a large number of $\mathrm{Atm}^{-/-}$spermatocytes had tightly clustered telomeres (Fig. 5c).

To be able to simultaneously stain telomeres and SCP3 proteins of the SC and to maintain nuclear structure, we performed FISH/immunostaining experiments on formaldehydefixed suspension nuclei. The distribution of DAPI bright chromocenters and the distribution mode of axial and lateral element proteins were used to identify cells at the various stages of prophase I. Premeiotic and preleptotene nuclei of
Atm null mice showed a scattered telomere distribution similar to that of the wild-type mice (data not shown).

A regional accumulation of telomeres was generally seen in spermatocytes displaying a leptotene/zygotene-like arrangement of axial cores (Fig. 6a and b). The frequency of nuclei with a few large telomere cluster signals was observed in only $0.5 \%$ of nuclei from testis suspension of normal mice. These observations match earlier reports and the assumption that the bouquet is a transient stage during early mouse prophase (75, 85). $\mathrm{Atm}^{-1-}$ spermatocytes with aberrant synapsis, on the other hand, often exhibited a bouquet arrangement (Fig. 6c and d), a three-dimensional organization motif rarely seen in spermatocytes of normal mice (see above and reference 25 and 75). The frequency of $\mathrm{Atm}^{-/-}$spermatocytes with extensive synapsis and locally accumulated telomeres was up to $50 \%$ in suspension slides (Fig. 6d; see also Fig. 3e), while this signal arrangement was encountered in only $7 \%$ of control spermatocytes. Many of the $\mathrm{Atm}^{-1-}$ spermatocyte nuclei contained a large chromocenter and displayed short, strong SCP3 signals at and around the accumulated telomeres (Fig. 6c), as judged from the colocalization of FISH and SC signals. This distribution contrasts with extensive and scattered axial core and SC formation in the polarized spermatocytes of normal mice (Fig. $6 b)$.

Telomere nuclear matrix interactions are altered in $\mathrm{Atm}^{-1-}$ spermatocytes. Telomeres are attached to the nuclear matrix of somatic cells $(19,44,81)$. Since such interactions may influence meiotic telomere mobility, we set out to characterize nuclear matrix-telomere interactions in spermatocytes derived from Atm null and control mice. To characterize the nature of telomere anchorage in spermatocytes obtained from Atm null and control mice, leptotene/zygotene cells were collected by elutriation and processed by the LIS procedure (22). The resulting halos were cleaved with StyI and probed with telomere TTAGGG repeats (Fig. 7). It was found that normal mice had about $50 \%$ of the telomeric DNA repeats associated with the nuclear matrix (P fraction), with $50 \%$ in the soluble $(\mathrm{S})$ fraction. The summation of the $\mathrm{P}$ and $\mathrm{S}$ fractions was equal to the total telomeric DNA, suggesting that the telomeric DNA was retained during the extraction procedure. In contrast to normal mice, spermatocytes of Atm null mice had more than $89 \%$ of the telomeric DNA repeats associated with the nuclear matrix and only $11 \%$ in the $\mathrm{S}$ fraction. The ratio between the $\mathrm{S}$ and $\mathrm{P}$ fractions is about 1:8 in spermatocytes of Atm null mice, compared to 1:1 in normal mice. These results suggest that the major portion of telomere repeats in Atm null spermatocytes remain associated with the nuclear matrix and that Atm influences this attachment in some way.

Telomerase activity in $\mathrm{Atm}^{-1-}$ spermatocytes. Whether the elevated interactions between telomeres and nuclear matrix could be attributed to telomerase or TRF is not known. It is 

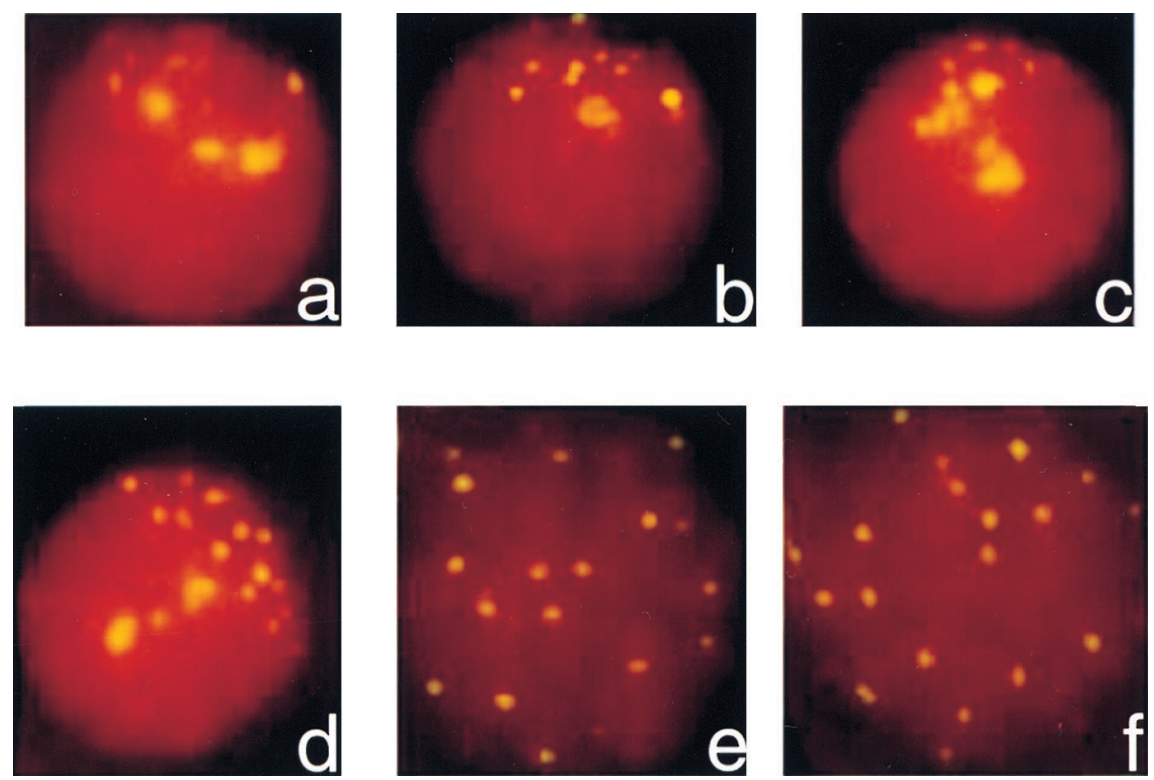

FIG. 5. Spermatocytes showing telomere clustering and subsequent separation of telomeres in postleptotene stage of meiosis prophase I as detected by the TTAGGG probe and propidium iodide used as counterstain. (a and b) Spermatocytes of control mice at leptotene/zygotene stage. (c) Spermatocyte of Atm $^{-/-}$mice at leptotene/zygotene stage. Note that panels a to $\mathrm{c} \mathrm{have} \mathrm{the} \mathrm{fewest} \mathrm{telomere} \mathrm{signals} \mathrm{but} \mathrm{each} \mathrm{signal} \mathrm{is} \mathrm{created} \mathrm{by} \mathrm{numerous} \mathrm{closely} \mathrm{spaced} \mathrm{signals.} \mathrm{Panels} \mathrm{d}$ to $\mathrm{f}$ show increased telomere signal numbers in cells from control mice with disperse telomere arrangement, as the clustered telomeres have organized in proper pairs. Such telomere dispersal at pachytene was rarely seen in $\mathrm{Atm}^{-/-}$spermatocytes.

known that ATM function influences telomere metabolism (80). To determine whether inactivation of Atm influences germ line telomerase activity, we examined protein extracts from seminiferous tubules of mice of the different genotypes. Telomerase activities in $\mathrm{Atm}^{-1-}$ and control mice were very similar (data not shown), which excludes a potential link between telomerase, Atm, and meiotic telomeres.

Expression of TRF1 and other genes in $\mathrm{Atm}^{-1-}$ spermatocytes. The human TRF1 protein binds with telomeres and shows homology with the telomeric fission yeast Tazl-encoded protein $(14,17,58)$. Recently, it has been demonstrated that fission yeast Tazl is required for meiotic telomere clustering (17). In vitro studies demonstrated that human TRF1 promotes parallel pairing of TTAGGG arrays, and thus TRF1 may have an architectural role at telomeres (28). To determine whether the Atm gene has any influence on the expression of TRF1 in mouse testes, we used reverse transcription-PCR and a slot blot approach to quantitate the expression of TRF1 in testes. We found-similar levels of TRF1 expression at the transcriptional level in testis of $\mathrm{Atm}^{-1-}$ and control mice (data not shown).

An attempt to further identify gene products that might be involved in defective meiosis in Atm null mice by Atlas cDNA microarray analysis, which monitors 588 genes, revealed similar expression of these genes in testes from Atm null and control mice (data not shown).

\section{DISCUSSION}

We have investigated the effects of inactivation of Atm on telomere clustering during male mouse meiosis. Our search was prompted by the observation that cells derived from A-T individuals show, among other features, an altered telomere metabolism and structure $(61,63,80,81)$. Telomere FISH to spermatocytes I of Atm null mice revealed that premeiotic and leptotene $\mathrm{Atm}^{-1-}$ mice nuclei are similar in telomere distribution and signal number to control mice (74a). Spermatocytes I of $\mathrm{Atm}^{-1-}$ mice, however, showed aberrant synapsis and telomere distribution, in that undisrupted spermatocyte nuclei frequently displayed clustered telomeres and a large chromocenter. SC immunostaining in combination with telomere FISH to these nuclei revealed fragmentary, strong SCP3 signals at and around the clustered telomeres, with the SC protein signals often aberrantly extending between several chromosome ends. Such a distribution of SC proteins and telomeres was not observed in spermatocytes of normal mice, where synapsis has been shown to initiate more internally (references 29 and 75 and this investigation) and is usually delayed at the heterochromatic proximal ends of the acrocentric mouse chromosomes $(2 n=40$ [86]). In male mouse meiosis, a bouquet arrangement of chromosome ends resolves soon after the initiation of synapsis (early zygotene) (75) and renders only a very low percentage of bouquet nuclei readily detectable (25). The higher frequency of spermatocytes with locally clustered telomeres encountered in $\mathrm{Atm}^{-1-}$ testes preparations suggest that the bouquet arrangement is maintained for a considerably longer period or is arrested in the absence of functional ATM protein. The prevalence of a bouquet arrangement could result from pairing partner switches, nonhomologous synapsis and/or illegitimate recombination events $(4,5)$ which interconnect accumulated chromosome ends at the cluster site, thereby preventing their dispersion during zygotene. Since telomere clustering occurs normally at the leptotene/zygotene transition (for a review, see reference 21), an elevated number of spermatocyte I nuclei showing a bouquet arrangement could also be a consequence of an arrest during leptotene/zygotene stages of meiotic prophase. This timing would be consistent with reports that the spermatogenic arrest in $\mathrm{Atm}^{-1-}$ animals occurs as early as leptotene or zygotene $(5,96)$.

Cells derived from A-T individuals show a prominent defect at chromosome ends in the form of chromosome end-to-end associations seen at metaphase as well as prematurely condensed chromosomes of $\mathrm{G}_{1}$ - and $\mathrm{G}_{2}$-phase cells. Frequency of cells with chromosome end associations decreases as cells pass 

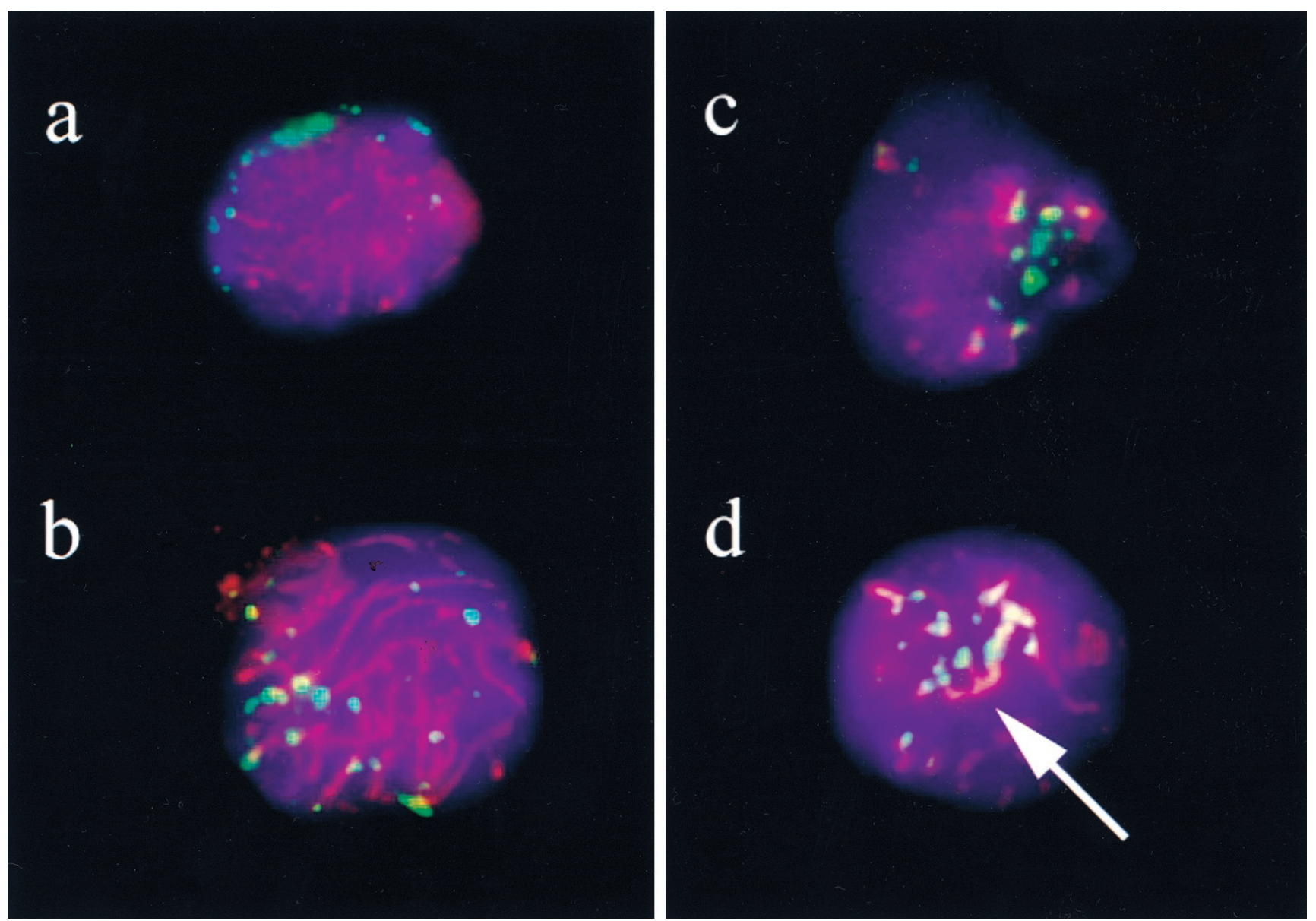

FIG. 6. Telomere FISH (green) and simultaneous SCP3 immunostaining (red) to structurally preserved bouquet spermatocytes of normal (a and b) and $\mathrm{Atm}{ }^{-}-$ (c and d) spermatocyte nuclei. DAPI (blue) marks the nuclear outline. (a) Leptotene/early zygotene nucleus with partially clustered telomeres and numerous axial core fragments; (b) zygotene nucleus with partially clustered telomeres and extensive synapsis; (c) polarized Atm $^{-/-}$spermatocyte with clustered telomeres and aberrant large SC-protein signals at and near the telomeres (yellow indicates color overlap); (d) Atm ${ }^{-1-}$ spermatocyte nucleus with clustered telomeres and aberrant synapsis (arrow denotes an SC stretch which connects at least three telomere-proximal axial cores).

from $\mathrm{G}_{1}$ phase to metaphase, suggesting that chromosome end associations are not permanent structures and probably do not involve covalent interactions. Whether the chromosome end associations are the cause for or the result of the accelerated loss of telomeres in A-T cells is unclear (50, 61, 63, 80, 93). Since the Atm gene has a PI-3 kinase domain, it is possible that the chromosome end associations defect are due to a defective kinase activity. Recently, we have reported that the ATM gene influences chromosome end associations as well as telomere length (80); however it is not clear how chromosome end associations are formed in cells derived from A-T individuals. We have recently shown that such cells have altered telomere chromatin and nuclear interactions (81). It is possible that altered telomere chromatin and nuclear matrix interactions influence telomere metabolism in somatic cells and telomere movement in meiotic cells, leading to a failure of normal telomere dispersion after bouquet formation and early prophase I.

ATM protein has been shown to be associated with chromatin (24), and ATM may be involved in the control of recombination $(5,65)$. The abrogation of $\mathrm{Atm}$ function results in meiotic prophase arrest associated with aberrant synapsis and fragmentation of SCs (references 5, 34, and 65 and this study). ATM also shows some homology to TEL1 and MEC1 genes of budding yeast, which are involved in telomere maintenance
(27) and meiotic and mitotic cell cycle check point control (46). Since Atm- and Dmc1-deficient mice $(64,97)$ as well as many recombination mutants of budding yeast fail to form normal SCs (for a review see reference 68), it is possible that an absence of Atm function alters the progression of recombination. Consistent with this hypothesis, proteins involved in normal recombination processes, like Rad51, DMC1, and Atr (66), are mislocalized as early as leptotene in $\mathrm{Atm}^{-1-}$ meiocytes (5). Aberrant synapsis and failure to form normal SCs seems to induce apoptosis (59) and fragmentation of chromosomes in $\mathrm{Atm}^{-1-}$ spermatocytes $(65,96)$. Given that telomere dispersion from the cluster site is delayed or prevented in $\mathrm{Atm}^{-1-}$ bouquet cells, SC fragmentation could result from the physical stress building up between immobile meiotic telomeres and dynamic chromosomes with unrepaired doublestrand breaks.

Recently, it was shown that a bouquet arrangement transiently forms during wild-type meiosis of budding yeast (91). The spo11 $(13,36)$ and rad50S recombination mutants of budding yeast (87), which fail to form normal SC $(42,95)$, form a chromosomal bouquet but fail to resolve this nuclear organization later at prophase, leading to elevated levels of bouquet nuclei (91). The timing and occurrence of a bouquet in yeast recombination mutants mirrors that in Atm-deficient sper- 


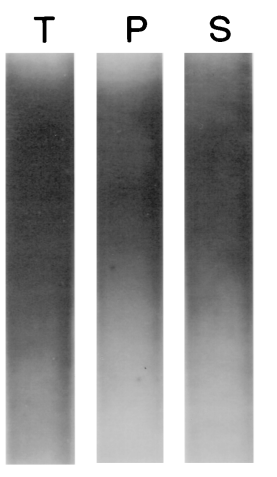

(a)
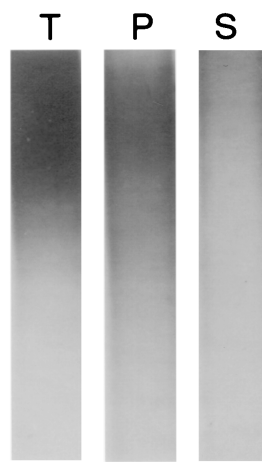

(b)
FIG. 7. Autoradiograph visualizing telomeric DNA. Halo preparations were digested with StyI and centrifuged to separate S and P telomeric sequences. Lanes show total (T; P plus S), S, and P telomeric DNA fractions in spermatogonia of Atm null (a) and control (b) mice. Lanes P and S for control mice and lanes $\mathrm{P}$ and $\mathrm{S}$ for Atm null mice represent telomeric DNA from similar numbers of halos. Note the difference in the $\mathrm{P} / \mathrm{S}$ fraction ratio between Atm null and control mouse cells.

matocytes, which also fail to resolve the bouquet arrangement. The observations that loss of all telomeres in fission yeast $\mathrm{TELI}^{+} \mathrm{rad}^{+}$double mutants prevents meiosis (57) and that telomeres support homologue search (67) strongly suggest that telomeres support homologue alignment. A persisting bouquet arrangement in $\mathrm{Atm}^{-1-}$ spermatocytes could contribute to the high levels of chromosome pairing at a telomere associated chromosome 8 region, despite the widely aberrant synapsis in $\mathrm{Atm}^{-1-}$ mice. This interpretation is consistent with the observation that recombination mutants of yeast form a bouquet (91) and undergo limited levels of homologue pairing $(42,56)$, which is elevated at telomeric regions (95).

Since ATM influences the organization of telomere chromatin in vegetative cells $(80,81)$ and telomeres have been shown to be tethered to the nuclear matrix in somatic cells $(19,44)$, we tested the interaction of telomeres with the nuclear matrix of spermatocytes from control and Atm-deficient mice. It was found that $90 \%$ of telomere repeats were associated with the nuclear matrix fraction of $\mathrm{Atm}^{-1-}$ spermatocytes, whereas only $50 \%$ of telomere repeats cofractionated with the matrix of control spermatocytes. One interpretation is that the altered persistent interaction of telomeres with the nuclear matrix could be a cause for the failure of resolution of telomere clustering in spermatocytes of $\mathrm{Atm}^{-1-}$ mice.

We considered the possibility that aberrant telomere clustering in Atm null mice is due to defective telomerase activity. That is, telomerase may be required for the synthesis of the correct telomere termini without which telomere ends might have defective interactions with the nuclear matrix. We found no differences in the telomerase activity between testes of Atm null and control mice, suggesting that the aberrant telomere clustering cannot be explained based on defective telomerase.

How Atm influences the interactions of telomeric DNA with the nuclear matrix as well as telomere clustering is not clear at present. There is growing evidence which suggests that both the shielding of telomeric ends and their elongation by telomerase are dependent on telomere binding proteins. Mammalian telomeres are packaged in telomere-specific chromatin (83). Telomere length homeostasis in yeast requires the binding of a protein along the telomeric tract $(39,45,49)$, and changes in the telomeric protein complex influence the stability of chromosome ends $(83,92)$. Three mammalian telomere binding proteins, namely, TRF1, TRF2, and PIN2 have been identified $(7,11,12,14,77,79)$. They have DNA binding properties with (TTAGGG) $)_{n}$ repeats in vitro irrespective of the presence of a DNA terminus, properties which are consistent with a presence along the ends of chromosomes. TRF1 has been implicated in the regulation of telomere length (92) and provides an architectural role at telomeres (28). Since it has been shown that protein localization is distorted in leptotene/ zygotene $\mathrm{Atm}^{-1-}$ spermatocytes (5), it is likely that ATM influences telomeres at the protein level. In agreement, TRF1 and 588 other genes were found to be similarly expressed in $\mathrm{Atm}^{-1-}$ and normal spermatocytes. Hence, it remains to be determined how the Atm gene product influences meiotic telomeres.

ATM belongs to a growing family of PI-3 protein kinases and shares some homology with the yeast MEK1 protein, which has been shown to be a meiosis specific kinase required for proper synapsis and sister chromatid cohesion during meiotic prophase (2). Since a major portion of telomere repeats in Atm null spermatocytes abnormally associated with the nuclear matrix, it may be speculated that Atm (besides other effects) is involved in this attachment. The altered interaction of telomere repeats with the meiotic nuclear matrix may be due to aberrant phosphorylation of as yet unknown components. Future investigations will have to determine whether ATM is involved in meiosis-dependent phosphorylation changes of telomeric proteins like tankyrase, a telomere-specific poly(ADPribose) polymerase that has recently been shown to reduce TRF1 telomere binding activity through poly(ADP)-ribosylation in vitro (84).

\section{ACKNOWLEDGMENTS}

This study was supported by NIH grant NS34746 and by Deutsche Forschungsgemeinschaft grant Sche 350/8-2.

Thanks are due to P. Leder, Harvard Medical School, Boston, Mass., for providing mating pairs of Atm heterozygote mice; to Lubomir Smilenov for technical help; and to C. Heyting, Wageningen, The Netherlands, for providing SCP3 antiserum. Thanks are also due to A. Wynshaw-Boris and T. Ashley for their comments.

\section{REFERENCES}

1. Ashley, T. 1994. Mammalian meiotic recombination: a reexamination. Hum. Genet. 94:587-593.

2. Bailis, J. M., and G. S. Roeder. 1998. Synaptonemal complex morphogenesis and sister-chromatid cohesion require MEK1-dependent phosphorylation of a meiotic chromosomal protein. Genes Dev. 12:3551-3563.

3. Barlow, C., S. Hirotsune, R. Paylor, M. Liyanage, M. Eckhaus, F. Collins, Y. Shiloh, J. N. Crawley, T. Ried, D. Tagel, and A. Wynshaw-Boris. 1996. Atm-deficient mice: a paradigm of ataxia-telangiectasia. Cell 86:159-171.

4. Barlow, C., M. Liyanage, P. B. Moens, C.-X. Deng, T. Ried, and A. WynshawBoris. 1997. Partial rescue of the prophase 1 defects of $\mathrm{Atm}$-deficient mice by p53 and p21 null alleles. Nat. Genet. 17:462-466.

5. Barlow, C., M. Liyanage, P. B. Moens, M. Tarsounas, K. Nagashima, K. Brown, S. P. Rottinghaus, S. P. Jackson, D. Tagle, T. Ried, and A. WynshawBoris. 1998. Atm deficiency results in severe meiotic disruption as early as leptonema of prophase. Development 125:4007-4017.

6. Baskaran, R., L. D. Wood, L. L. Whitaker, C. E. Canman, S. E. Morgan, Y. Xu, D. Baltimore, M. B. Kastan, and J. Wang. 1997. Ataxia telangiectasia mutant protein activates c-Abl tyrosine kinase in response to ionizing radiation. Nature 387:516-519.

7. Bilaud, T., C. Brun, K. Ancelin, C. E. Koering, T. Laroche, and E. Gilson. 1997. Telomeric localization of TRF2, a novel human telobox protein. Nat. Genet. 17:236-239.

8. Blackburn, E. H. 1991. Structure and function of telomeres. Nature 350: $569-573$.

9. Bridges, B. A., and D. G. Harnden. 1982. Ataxia telangiectasia: a cellular and molecular link between cancer, neuropathology, and immune deficiency. John Wiley, Chichester, England.

10. Brinkley, B. R., S. L. Brenner, J. M. Hall, A. Tousson, R. D. Balczon, and M. M. Valdivia. 1986. Arrangement of kinetochores in mouse cells during meiosis and spermiogenesis. Chromosoma 94:309-317.

11. Broccoli, D., L. Chong, S. Oelmann, A. A. Fernald, N. Marziliano, B. van 
Steensel, D. Kipling, M. M. Le Beau, and T. de Lange. 1997. Comparison of the human and mouse genes encoding the telomeric protein, TRF1: chromosomal localization, expression and conserved protein domains. Hum. Mol. Genet. 6:69-76.

12. Broccoli, D., A. Smogorzewska, L. Chong, and T. de Lange. 1997. Human telomeres contain two distinct Myb-related proteins TRF1 and TRF2. Nat. Genet. 17:231-235.

13. Cao, L., E. Alani, and N. Kleckner. 1990. A pathway for generation and processing of double-strand breaks during meiotic recombination in $\mathrm{S}$. cerevisiae. Cell 61:1089-1101.

14. Chong, L., B. van Steensel, D. Broccoli, H. Erdjument-Bromage, J. Hanish, O. Tempst, and T. de Lange. 1995. A human telomeric protein. Science 270:1663-1667.

15. Chua, P. R., and G. S. Roeder. 1997. Tam1, a telomere-associated meiotic protein, functions in chromosome synapsis and crossover interference. Genes Dev. 11:1786-1800.

16. Conrad, M. N., A. M. Dominguez, and M. E. Dresser. 1997. Ndj1p, a meiotic telomere protein required for normal chromosome synapsis and segregation in yeast. Science 276:1252-1255.

17. Cooper, J. P., Y. Watanabe, and P. Nurse. 1998. Fission yeast Taz1 protein is required for meiotic telomere clustering and recombination. Nature 392: 828-831.

18. Counter, C. M., A. A. Avilion, C. E. LeFeuvre, N. G. Stewart, C. W. Greider, C. B. Harley, and S. Bacchetti. 1992. Telomere shortening associated with chromosome instability is arrested in immortal cells which express telomerase activity. EMBO J. 11:1921-1929.

19. de Lange, T. 1992. Human telomeres are attached to the nuclear matrix. EMBO J. 11:717-724.

20. de Lange, T. 1998. Ending up with the right partner. Nature 392:753-754.

21. Dernburg, A. F., J. W. Sedat, W. Z. Cande, and H. W. Bass. 1995. The cytology of telomeres, p. 295-338. In E. H. Blackburn and C. W. Greider (ed.), Telomeres. Cold Spring Harbor monograph series. Cold Spring Harbor Laboratory, Cold Spring Harbor, N.Y.

22. Dijkwel, P. A., and J. L. Hamlin. 1988. Matrix attachment regions are positioned near replication initiation sites, genes, and an interamplicon junction in the amplified dihydrofolate reductase domain of Chinese hamster ovary cells. Mol. Cell. Biol. 8:5398-5409.

23. Elson, A., Y. Wang, C. J. Daugherty, C. C. Morton, F. Zhou, J. CamposTorres, and P. Leder. 1996. Pleiotropic defects in ataxia-telangiectasia protein-deficient mice. Proc. Natl. Acad. Sci. USA 93:13084-13089.

24. Gately, D. P., J. C. Hittle, G. K. T. Chan, and T. J. Yen. 1998. Characterization of ATM expression, localization, and associated DNA-dependent protein kinase activity. Mol. Biol. Cell. 9:2361-2374.

25. Glamann, J. 1986. Crossing over in the male mouse as analyzed by recombination nodules and bars. Carlsberg Res. Commun. 51:143-162.

26. Goetz, P., A. C. Chandley, and R. M. Speed. 1984. Morphological and temporal sequence of meiotic prophase development at puberty in the male mouse. J. Cell Sci. 65:249-263.

27. Greenwell, P. W., S. L. Kronmal, S. E. Porter, J. Gassenhuber, B. Obermaier, and T. D. Petes. 1995. TEL1, a gene involved in controlling telomere length in $S$. cerevisiae, is homologous to the human ataxia telangiectasia gene. Cell 82:823-829.

28. Griffith, J., A. Bianchi, and T. de Lange. 1998. TRF1 promotes parallel pairing of telomeric tracts in vitro. J. Mol. Biol. 278:79-88.

29. Guitart, M., M. D. Coll, M. Ponsa, and J. Egozcue. 1985. Sequential study of synaptonemal complexes in mouse spermatocytes by light and electron microscopy. Genetica 67:21-30.

30. Haaf, T., and D. C. Ward. 1995. Higher order nuclear structure in mammalian sperm revealed by in situ hybridization and extended chromatin fibers. Exp. Cell Res. 219:604-611.

31. Harnden, D. G. 1994. The nature of ataxia-telangiectasia: problems and perspectives. Int. J. Radiat. Biol. 66:S13-S19.

32. Hoekstra, M. F. 1997. Responses to DNA damage and regulation of cell cycle checkpoints by the ATM protein kinase family. Curr. Opin. Genet. Dev. 7:170-175.

33. Kastan, M. B., Q. Zhan, W. S. EI Deiry, F. Carrier, T. Jacks, W. V. Walsh, B. S. Plunkett, B. Vogelstein, and A. J. Fornace, Jr. 1992. A mammalian cell cycle checkpoint pathway utilizing p53 and GADD45 is defective in ataxiatelangiectasia. Cell 71:587-597.

34. Keegan, K. S., D. A. Holtzman, A. W. Plug, E. R. Christenson, E. E. Brainerd, G. Flaggs, N. J. Bentley, E. M. Taylor, M. S. Meyn, S. B. Moss, A. M. Carr, T. Ashley, and M. E. Hoekstra. 1996. The Atr and Atm protein kinases associate with different sites along meiotically pairing chromosomes. Genes Dev. 10:2423-2437.

35. Keith, C. T., and S. L. Schreiber. 1995. PIK-related kinases: DNA repair, recombination, and cell cycle checkpoint. Science 270:50-51.

36. Klapholz, S., C. S. Waddell, and R. E. Esposito. 1985. The role of the SPO11 gene in meiotic recombination in yeast. Genetics 110:187-216.

37. Ko, L. J., and C. Prives. 1996. p53: puzzle and paradigm. Genes Dev. 10:1054-1072.

38. Kojis, T. L., R. A. Gatti, and R. S. Sparkes. 1991. The cytogenetics of ataxia telangiectasia. Cancer Genet. Cytogenet. 56:143-156.
39. Kyrion, G., K. A. Boakye, and A. J. Lustig. 1992. C-terminal truncation of RAP1 results in the deregulation of telomere size, stability, and function in Saccharomyces cerevisiae. Mol. Cell. Biol. 12:5159-5173.

40. Lammers, J. H. M., H. H. Offenberg, M. van Aalderen, A. C. Vink, A. J. Dietrich, and C. Heyting. 1994. The gene encoding a major component of the lateral elements of synaptonemal complexes of the rat is related to X-linked lymphocyte-regulated genes. Mol. Cell. Biol. 14:1137-1146.

41. Loidl, J. 1990. The initiation of meiotic chromosome pairing: the cytological view. Genome 33:759-778.

42. Loidl, J., F. Klein, and H. Scherthan. 1994. Homologous pairing is reduced but not abolished in asynaptic mutants in yeast. J. Cell Biol. 125:1191-1200.

43. Lu, X., and D. P. Lane. 1993. Differential induction of transcriptionally active p53 following UV or ionizing radiation: defects in chromosome instability syndromes? Cell 75:765-778.

44. Luderus, M. E. E., B. van Steensel, L. Chong, O. C. M. Sibon, F. F. M Cremers, and T. de Lange. 1996. Structure, subnuclear distribution, and nuclear matrix association of the mammalian telomeric complex. J. Cell Biol. 135:867-881.

45. Lustig, A. J., S. Kurtz, and D. Shore. 1990. Involvement of the silencer and UAS binding protein RAP1 in regulation of telomere length. Science 250: 549-553.

46. Lydall, D., Y. Nikolsky, D. K. Bishop, and T. Weinert. 1996. A meiotic recombination checkpoint controlled by mitotic checkpoint genes. Nature 383:840-843.

47. Ma, C., S. Martin, B. Trask, and J. L. Hamlin. 1993. Sister chromatid fusion initiates amplification of the dihydrofolate reductase gene in Chinese hamster cells. Genes Dev. 7:605-620.

48. McClintock, B. 1941. The stability of broken ends of chromosomes of Zea mays. Genetics 26:234-282.

49. McEachern, M. J., and E. H. Blackburn. 1995. Runaway telomere elongation caused by telomerase RNA gene mutations. Nature 376:403-409.

50. Metcalf, J. A., J. Parkhill, L. Cambell, M. Stacey, P. Biggs, P. J. Byrd, and M. R. Taylor. 1996. Accelerated telomere shortening in ataxia telangiectasia. Nat. Genet. 13:350-353.

51. Meyn, M. S. 1995. Ataxia-telangiectasia and cellular responses to DNA damage. Cancer Res. 55:5991-6001.

52. Mirkovitch, J., M.-E. Mirault, and U. K. Laemmli. 1984. Organization of the higher-order chromatin loop: specific DNA attachment sites on nuclear scaffold. Cell 39:223-232.

53. Moens, P. B., and R. E. Pearlman. 1990. Telomere and centromere DNA are associated with the cores of meiotic prophase chromosomes. Chromosoma 100:8-14.

54. Moses, M. J. 1968. Synaptonemal complex. Annu. Rev. Genet. 2:363-412.

55. Muller, H. J. 1938. The remaking of chromosomes. Collecting Net (Woods Hole, Mass.) 13:181-195.

56. Nag, D., H. Scherthan, B. Rockmill, J. Bhargava, and G. S. Roeder. 1995. Heteroduplex DNA formation and homolog pairing in yeast meiotic mutants. Genetics 141:75-86.

57. Naito, T., A. Matsuura, and F. Ishikawa. 1998. Circular chromosome formation in a fission yeast mutant defective in two ATM homologues. Nat. Genet. 20:203-206.

58. Nimmo, E. R., A. L. Pidoux, P. E. Perry, and R. C. Allshire. 1998. Defective meiosis in telomere-silencing mutants of Schizosaccharomyces pombe. Nature 392:825-828.

59. Odorisio, T., T. A. Rodriguez, E. P. Evans, A. R. Clarke, and P. S. Burgoyne. 1998. The meiotic checkpoint monitoring synapsis eliminates spermatocytes via p53-independent apoptosis. Nat. Genet. 18:257-261.

60. Pandita, T. K., and D. DeRubeis. 1995. Spontaneous amplification of interstitial telomeric bands in Chinese hamster ovary cells. Cytogenet. Cell Genet. 68:95-101.

61. Pandita, T. K., E. J. Hall, T. K. Hei, M. A. Piatyszek, W. E. Wright, C. Q. Piao, R. K. Pandita, J. V. Willey, C. R. Geard, M. B. Kastan, and J. W. Shay. 1996. Chromosome end-to-end associations and telomerase activity during cancer progression in human cells after treatment with $\alpha$-particles simulating radon progeny. Oncogene 13:1423-1430.

62. Pandita, T. K., and W. N. Hittelman. 1992. Initial chromosome damage but not DNA damage is greater in ataxia telangiectasia cells. Radiat. Res. 130: 94-103.

63. Pandita, T. K., S. Pathak, and C. Geard. 1995. Chromosome end association, telomeres and telomerase activity in ataxia telangiectasia cells. Cytogenet. Cell Genet. 71:86-93.

64. Pittman, D. L., J. Cobb, K. J. Schimenti, L. A. Wilson, D. M. Cooper, E. Brignull, M. A. Handel, and J. C. Schimenti. 1998. Meiotic prophase arrest with failure of chromosome synapsis in mice deficient for Dmc1, a germlinespecific RecA homolog. Mol. Cell 1:697-705.

65. Plug, A. W., A. H. Peters, Y. Xu, K. S. Keegan, M. F. Hoekstra, D. Baltimore, P. de Boer, and T. Ashley. 1997. ATM and RPA in meiotic chromosome synapsis and recombination. Nat. Genet. 17:457-461.

66. Plug, A. W., A. H. Peters, K. S. Keegan, M. F. Hoekstra, P. de Boer, and T. Ashley. 1998. Changes in protein composition of meiotic nodules during mammalian meiosis. J. Cell Sci. 111:413-423.

67. Rockmill, B., and G. S. Roeder. 1998. Telomere-mediated chromosome 
pairing during meiosis in budding yeast. Genes Dev. 12:2574-2586.

68. Roeder, G. S. 1997. Meiotic chromosomes: it takes two to tango. Genes Dev. 11:2600-2621.

69. Sandell, L. L., and V. A. Zakian. 1993. Loss of a yeast telomere: arrest, recovery and chromosome loss. Cell 75:729-739.

70. Savitsky, K., A. Bar-Shira, S. Gilad, G. Rotman, Y. Ziv, L. Vanagaite, D. A. Tagle, S. Smith, T. Uziel, S. Sfez, M. Ashkenazi, I. Pecker, M. Frydman, R. Harnik, S. R. Patanjali, A. Simmons, G. A. Clines, A. Sartiel, R. A. Gatti, L. Chessa, O. Sanyal, M. F. Lavin, N. G. J. Jaspers, A. M. R. Taylor, C. F. Arlett, T. Miki, S. M. Weissman, M. Lovett, F. S. Collins, and Y. Shiloh. 1995. A single ataxia telangiectasia gene with a product similar to PI-3 kinase. Science 268:1749-1753.

71. Savitsky, K., S. Sfez, D. A. Tagel, Y. Ziv, A. Sartiel, F. S. Collins, Y. Shiloh, and G. Rotman. 1995. The complete sequence of the coding region of the ATM gene reveals similarity to cell cycle regulators in different species. Hum. Mol. Genet. 4:2025-2032.

72. Sawant, S. G., V. Gregoire, C. B. Umbricht, S. Cvilic, S. Sukumar, and T. K. Pandita. 1999. Telomerase activity as a measure for monitoring radiocurability of tumor cells. FASEB J. 13:1047-1054.

73. Scherthan, H. 1997. Chromosome behavior in earliest meiotic prophase. Chromosomes Today 12:217-248.

74. Scherthan, H., J. Bahler, and J. Kohli. 1994. Dynamic chromosome organization and pairing during meiotic prophase of fission yeast. J. Cell Biol. 127:273-285.

74a.Scherthan, H., and T. K. Pandita. Unpublished data.

75. Scherthan, H., S. Weich, H. Schwegler, C. Heyting, M. Harle, and T. Cremer. 1996. Centromere and telomere movement during early prophase of mouse and man are associated with the onset of chromosome pairing. J. Cell Sci. 134:1109-1125.

76. Shafman, T., K. K. Khanna, P. Kedar, K. Spring, S. Kozlov, T. Yen, K. Hobson, M. Gatei, N. Zhang, D. Watters, M. Egerton, Y. Shiloh, S. Kharbanda, D. Kufe, and M. F. Lavin. 1997. Interactions between ATM protein and c-Abl in response to DNA damage. Nature 387:520-523.

77. Shen, M., C. Haggblom, M. Vogt, T. Hunter, and K. P. Lu. 1997. Characterization and cell cycle regulation of the related human telomeric proteins Pin2 and TRF1 suggest a role in mitosis. Proc. Natl. Acad. Sci. USA 94: 13618-13623.

78. Shiloh, Y. 1995. Ataxia-telangiectasia: closer to unraveling the mystery. Eur. J. Hum. Genet. 3:116-138.

79. Smilenov, L. B., W. Mellado, P. H. Rao, S. G. Sawant, C. B. Umbricht, S. Sukumar, and T. K. Pandita. 1998. Molecular cloning and chromosomal localization of Chinese hamster telomeric protein chTRF1: its potential role in chromosomal instability. Oncogene 17:2137-2142.

80. Smilenov, L. B., S. E. Morgan, W. Mellado, S. G. Sawant, M. B. Kastan, and T. K. Pandita. 1997. Influence of ATM function on telomere metabolism. Oncogene 15:2659-2665.

81. Smilenov, L. B., S. Dhar, and T. K. Pandita. Altered telomere nuclear matrix interactions and nucleosomal periodicity in ataxia telangiectasia cells. Submitted for publication.
82. Smith, G. R., M. B. Stark, P. A. Gorman, and G. R. Stark. 1992. Fusion near telomeres occur very early in the amplification of CAD genes in Syrian hamster cells. Proc. Natl. Acad. Sci. USA 89:5427-5431.

83. Smith, S., and T. de Lange. 1997. TRF1, a mammalian telomeric protein. Trends Genet. 13:21-26.

84. Smith, S., I. Giriat, A. Schmitt, and T. de Lange. 1998. Tankyrase, a poly(ADP-ribose) polymerase at human telomeres. Science 282:1484-1487.

85. Speed, R. M. 1982. Meiosis in the foetal mouse ovary. I. An analysis at the light microscope level using surface-spreading. Chromosoma 85:427-437.

86. Stack, S. M. 1984. Heterochromatin, the synaptonemal complex and crossing over. J. Cell Sci. 71:159-176.

87. Sun, H., D. Dawson, and J. W. Szostak. 1991. Genetic and physical analyses of sister chromatid exchange in yeast meiosis. Mol. Cell. Biol. 11:6328-6336.

88. Svoboda, A., J. Bahler, and J. Kohli. 1995. Microtubule-driven nuclear movements and linear elements as meiosis-specific characteristics of the fission yeasts Schizosaccharomyces versatilis and Schizosaccharomyces pombe. Chromosoma 104:203-214.

89. Taylor, A. M. R. 1982. Cytogenetics of ataxia-telangiectasia, p. 53-81. In B. A. Bridges and D. G. Harden (ed.), Ataxia-telangiectasia. A cellular and molecular link between cancer, neuropathology, and immune deficiency. John Wiley, Chichester, England.

90. Therman, E., and G. E. Sarto. 1977. Premeiotic and early meiotic stages in the pollen mother cells of Eremurus and in human embryonic oocytes. Hum. Genet. 35:137-151.

91. Trelles-Sticken, E., J. Loidl, and H. Scherthan. 1999. Bouquet formation in budding yeast: initiation of recombination is not required for meiotic telomere clustering. J. Cell Sci. 112:651-658.

92. van Steensel, B., and T. de Lange. 1997. Control of telomere length by the human telomeric protein TRF1. Nature 385:740-743.

93. Vaziri, H., M. D. West, R. C. Allsopp, T. S. Davidson, Y.-S. Wu, C. H. Arrowsmith, G. G. Priorier, and S. Benchimol. 1997. ATM-dependent telomere loss in aging human diploid fibroblasts and DNA damage lead to the post-translational activation of $\mathrm{p} 53$ protein involving poly(ADP-ribose) polymerase. EMBO J. 16:6018-6033.

94. von Wettstein, D., S. W. Rasmussen, and P. B. Holm. 1984. The synaptonemal complex in genetic segregation. Annu. Rev. Genet. 18:331-413.

95. Weiner, B. M., and N. Kleckner. 1994. Chromosome pairing via multiple interstitial interactions before and during meiosis in yeast. Cell 77:977-991.

96. Xu, Y., T. Ashley, E. E. Brainerd, R. T. Bronson, M. S. Meyn, and D. Baltimore. 1996. Targeted disruption of ATM leads to growth retardation, chromosomal fragmentation during meiosis, immune defects, and thymic lymphoma. Genes Dev. 10:2401-2410.

97. Yoshida, K., G. Kondoh, Y. Matsuda, T. Habu, Y. Nishimune, and T. Morita. 1998. The mouse RecA-like gene Dmc1 is required for homologous chromosome synapsis during meiosis. Mol. Cell 1:707-718.

98. Zakian, V. A. 1995. Saccharomyces telomeres: function, structure and replication, p. 107-138. In E. H. Blackburn and C. W. Greider (ed.), Telomeres. Cold Spring Harbor Laboratory Press, Cold Spring Harbor, N.Y. 